\title{
LA DIMENSIÓN POLÍTICA, SOCIOECONÓMICA Y RELIGIOSA DE LA REDENCIÓN DE CAUTIVOS EN LA BAJA EDAD MEDIA: PODER LAICO Y ÓRDENES RELIGIOSAS
}

Juan A. Prieto Sayagués ${ }^{1}$

Universidad Complutense de Madrid

Recibido: 25 de noviembre de 2019

Aceptado: 23 de julio de 2020

\begin{abstract}
Resumen
En este trabajo analizamos las relaciones de benefactoría entre el poder laico y las órdenes redentoras de cautivos -Trinidad y Merced- y el componente político e identitario de las mismas. Se abordan las dinámicas de la redención y las vías económicas por las que estas órdenes consiguieron recaudar el dinero necesario para llevar a cabo su cometido. Se expone la participación de otras órdenes y monasterios en la redención, dando origen al a la popularización de los milagros asociados a sus Vírgenes o santos titulares y las consiguientes peregrinaciones a estos cenobios.
\end{abstract}

\section{Palabras clave}

Órdenes redentoras, redención de cautivos, poder laico, Guadalupe y Santo Domingo de Silos, milagros y peregrinaciones.

\begin{abstract}
In this article we analyse the relations of benefactoria between the secular power and the redeeming orders of captives -Trinitarians and Mercedarians- as well as their political and identity component. We address the dynamics of redemption and the economic ways by which these orders managed to raise the money necessary to carry out their task. The participation of other orders and monasteries in the redemption is exposed, giving rise to the popularization of the miracles associated with their Virgin or titular saints and the consequent pilgrimages to these monasteries.
\end{abstract}

\section{Keywords}

Redemptive orders, redemption of captives, lay power, Guadalupe and Santo Domingo de Silos, miracles and pilgrimages.

\section{Résumé}

Dans cet article, on analyse les relations de bienfaisance entre le pouvoir séculier et les ordres de rachat des captifs - Trinitaires et Mercédaires- et leur dimension politique et identitaire. On y aborde la dynamique de rachat et les moyens économiques par lesquels ces ordres ont réussi à réunir les

1 Correo electrónico: juananpr@ucm.es. OrCID: https://orcid.org/0000-0001-9286-2182. 
fonds nécessaires à l'accomplissement de leurs tâches. On y expose la participation d'autres ordres et monastères à leur rédemption, de même que la popularisation des miracles associés à leur Vierge ou aux saints titulaires et aux pèlerinages liés à ces monastères.

\section{Mots clés}

Trinitaires et mercédaires, rachat des captifs, pouvoir laïc, Guadalupe et Santo Domingo de Silos, miracles et pèlerinages.

\section{Introducción}

El avance cristiano hacia el sur hizo aparecer la Frontera, el cautiverio, las órdenes redentoras - Trinidad y Merced-y los milagros de monasterios relativos a dicha cuestión ${ }^{2}$. Estas órdenes negociaban con los musulmanes el pago de los rescates, ayudaban económicamente a los familiares de los cautivos y sus autoridades elegían a los frailes redentores, quienes debían ser "maduros, virtuosos, formados, prudentes, sagaces y misericordiosos" para negociar y no ser engañados 3 .

Las Partidas diferencian a un preso y un cautivo: captivos son llamados, por derecho, aquellos que caen en prisión de omes de otra creencia. Por tanto, el cautiverio tenía que ver con la religión, siendo una pérdida de libertad provisional a la espera de un rescate, mientras que el esclavo pertenecía a otra persona. Entre las cinco razones que obligaban las Partidas a una persona a liberar al cautivo, estaban ser de la misma religión

\footnotetext{
2 Este trabajo se enmarca en los Proyectos de Investigación "Expresiones de la cultura política peninsular en las relaciones de conflicto (Corona de Castilla, 1230-1504)", ref. HAR2016-76174-P, del Programa Estatal de Fomento de la Investigación Científica y Técnica de Excelencia y "El ejercicio del poder: espacios, agentes y escrituras (siglos XI-XV)", ref. HAR2017-84718-P, financiado por el MINECO/AEI/ FEDER (UE).

3 Entre los actos que acompañaban a una campaña redentora, recogidos en las constituciones de la Merced de 1272, estaban la salvaguarda del poder civil a los frailes, la celebración de ceremonias y oficios religiosos, el anuncio de la redención al pueblo, la recogida de limosnas y la recepción en procesión cuando llegaban con los redimidos portando las vestimentas del cautiverio como acto propagandístico. Estos quedaban al servicio de la orden por un periodo de dos o seis meses para acompañar a los redentores en la colecta de limosnas. Después de ese tiempo se les rasuraba la barba, se les cortaba el cabello y se les daba el vestuario y alimentos necesarios para el regreso a sus casas. Los religiosos escribían un informe de su labor y, si no se empleaba el dinero en los cautivos, se devolvía a los donantes, en Ángeles GARCía DE la Borbolla, "Santo Domingo de Silos, el santo de la frontera: la imagen de la santidad a partir de las fuentes hagiográficas castellano-leonesas del siglo XIII", Anuario de Estudios Medievales, 31/1 (2001), pp. 137-139; M. ' Eugenia DíAz TEnA, "Los Reyes Católicos y la redención de cautivos en un milagro mariano de finales del siglo XV (I)", Literatura medieval y renacentista en España: líneas y pautas, Natalia Fernández Rodríguez y María Fernández Ferreiro (coords.), SEMYR, Salamanca, 2012, p. 502; Albert Cassanyes Roig, "La Iglesia de Mallorca y la redención de cautivos en la Baja Edad Media", en Espacio, Tiempo y Forma. Serie III. Historia Medieval, 32 (2019), pp. 107, 112-113 y 116; Emilio CABrerA, "De nuevo sobre los cautivos cristianos en el reino de Granada", Meridies, III (1996), p. 138; M. Teresa RuIz BARrERA, "Redención de cautivos. Una especial obra de misericordia de la Orden de la Merced", La Iglesia española y las instituciones de caridad, Francisco Javier Campos y Fernández de Sevilla (coord.), Instituto Escurialense de Investigaciones Históricas y Artísticas, El Escorial, 2006, pp. 844-846.
} 
o linaje y ser herederos por testamento, aun no siendo parientes. De igual manera, la monarquía debía velar por los rescates de cautivos de sus reinos ${ }^{4}$.

Por tanto, por las razones que acabamos de señalar y las que comentaremos a continuación, los poderes laicos tuvieron la obligación de contribuir a la redención de cautivos a través de diferentes vías. En este trabajo analizaremos aquellas que implicaron a las órdenes redentoras, sus monasterios y religiosos y, en menor medida, a los de otras órdenes.

\section{Fundadores y bienhechores de las órdenes redentoras en Castilla y Aragón}

Las órdenes de la Merced y de la Trinidad, tuvieron una andadura diferente en la Península Ibérica. La Merced surgió con el patrocinio de la casa real aragonesa, cuyos miembros también fundaron varios conventos. Jaime I cedió el hospital de Santa Eulalia de Barcelona para fundar el primer cenobio. Jaime II erigió el de Menorca (1286), Alfonso IV el de Cerdeña (1335), el infante Martín el de Tárrega (1383) y Alfonso V el de Nápoles (1442). De su llegada a Murcia no hay documentación, aunque posiblemente lo hicieran acompañando a Jaime I, siendo la primera mención la donación del infante don Manuel de los baños viejos y el osario de la aljama de Elche para edificar su capilla (27/VI/1270). En 1404 se erigió la encomienda de Santa Lucía de Elche, surgiendo problemas con el obispo de Cartagena, Pablo de Santa María, quien intentaba ejercer su jurisdicción sobre ella; el 28 de septiembre Martín I le recordó que, por bulas de la Santa Sede le correspondía a la Corona como fundadora de la Orden, rogando que no se entrometiese o le confiscaría las rentas que percibiese de sus tierras. En Menorca puede que se asentasen tras la conquista de Alfonso el Liberal (1287); cuando la isla pasó al Reino de Mallorca en el tratado de Agnagni de 1295, Jaime II confiscó sus bienes y hasta 1307 no se les autorizó a pedir limosna. Además de estas fundaciones, los reyes aragoneses concedieron numerosos privilegios a la orden 5 .

\footnotetext{
La costumbre de la captura y posterior liberación tras el pago del rescate era respetada pero no obligatoria. Si los familiares o herederos no trataban de liberar al cautivo podían ser desheredados, excepto los hijos menores de 18 años, en Andrés Serrano del Toro, El Cautiverio en la Frontera Murciano-Granadina en el siglo XIV: un Fenómeno Socio-Económico, Tesis Doctoral, Universidad de Murcia, 2015, p. XLIXLIV; José Manuel Calderón Ortega y Francisco Javier Díaz GonzÁlez, "El rescate de prisioneros y cautivos durante la Edad Media hispánica. Aproximación a su estudio", HID, 38 (2011), pp. 17 y 23-27.

5 Jaime I confirmó a la Merced de Barcelona sus posesiones (1250) y se autoproclamó fundador de la orden (1255). Jaime II expidió 99 documentos exponiendo su patronato y los tomó bajo su protección; los eximió de tributos, intercedió por los frailes cautivos, los eximió del cobro de impuestos por pasar cereales y animales para la redención y actuó contra los falsos cautivos. Jaime II escribió a Bonifacio VIII aludiendo a la implicación de Jaime I en los comienzos de la orden (4/I/1301). Pedro IV expidió 149 documentos y Juan I, 81. Este último pidió prestado el caballo al General para su boda, contó con numerosos mercedarios en su Casa, mejoró los conventos, intervino en sus asuntos internos, los defendió ante los abusos de obispos y otras órdenes y los eximió del diezmo. De Martín I se conservan un centenar de documentos. El general Antonio Caxal fue embajador de Fernando I en varias misiones y en el concilio de Constanza. Fray Juan Seglars acompañó a Alfonso V en la conquista de Nápoles, fray Juan Galicant fue su embajador ante Ottumen, rey de Túnez y tuvo por consejero a Nadal Gaver, en Guillermo VÁzQuez
} 
En Castilla la presencia mercedaria se constata en el reinado de Fernando III, cuando dirigieron una redención en Granada (1222). El rey promovió su instalación en Sevilla después de la participación de la orden en su conquista y Alfonso X les concedió tierras en Mula, Córdoba, Vejer, Arjona y Almansa. Pese al poco calado que tuvo la orden en Castilla, Sancho IV, Fernando IV (1311 y 1312) y Enrique II (1373) concedieron privilegios. Juan II se limitó a confirmar los anteriores (1437, 1438 y 1449), síntoma de su incumplimiento. En cuanto a las fundaciones, la infanta Isabel, hija de Sancho IV, erigió el convento de Guadalajara (1306), Alfonso XI el de Algeciras, y la reina Beatriz de Portugal amplió el de Valladolid (1384-1394) y tuvo en mente fundar otro convento de mercedarias y reformar el primero de ellos (1414) ${ }^{6}$.

El linaje que mayores vínculos tuvo con la Merced fue el de los Pecha: Elvira Martínez fundó el convento de Segovia (1367) e hizo donaciones a San Antolín de Guadalajara, al igual que otros miembros de su familia. La otra fundación de la que tenemos constancia fue iniciativa de los Ayala. Fernán Pérez de Ayala y su hijo Pedro, entregaron la iglesia de Santa María de Burceña a la orden (1382). Otros nobles se limitaron a hacer donaciones esporádicas como las de la condesa de Castañeda a los mercedarios de Burgos y Valladolid (1441), Teresa de Luna a Santa María de la Fuensanta de Cuenca

NúÑ̃z, Manual de la Historia de la Orden de Nuestra Señora de la Merced, Editorial Católica Toledana, Toledo, 1931, pp. 122-124, 209, 239-240, 250 y 330-341; SERRANo, El Cautiverio, pp. CDXXIX-CDXXXII; Celia SAncho Gómez, "Violencia y cautiverio al sur del reino de Valencia a principios del siglo XV: Elche como un observatorio de una villa de frontera", Norba. Revista de Historia, 25-26 (2012-2013), pp. 329-330; Cassanyes, "La Iglesia...", pp. 114-115; Vicent F. Zuriaga Senent, La imagen devocional en la orden de Nuestra Señora de la Merced. Tradición, Formación, Continuidad y Variantes, Tesis Doctoral, Universitat de València, 2005, pp. 45-46 y 66-70.

6 Fernando IV ordenó a las autoridades del reino respetar sus privilegios y evitar los abusos de los demandadores de ultramar y de la Cruzada; recibir la mayor manda en caso de omisión en los testamentos; el quinto de los que muriesen sin testar; les permitió poner bacines y tazas en las iglesias; ordenó no tomar el tercio de lo que mandaban para la redención en lugares de las órdenes; requisar a los que demandaban en nombre de la orden falsamente y entregar a la orden lo incautado; cortar el pelo y las barbas y tomar lo que llevasen encima a los falsos redimidos; dar a los frailes buena posada y obligar a los vecinos a escuchar sus sermones (1311). El privilegio de 1312 es similar incluyendo algunas cláusulas. El privilegio de Enrique II de 1372 fue el más amplio de todos: confirmó los anteriores, tomó a la orden bajo su protección y añadió nuevas cláusulas como dar posada, dinero y viandas al provincial y religiosos; poner un guía cuando fueran a redimir cautivos para evitar robos; no pedir a los cautivos derechos por las cosas que llevasen ni por otro motivo; detener y entregar al provincial, para ser juzgados, a quienes se hicieran pasar por frailes recaudando dinero para la redención; eximió de tercio, cuarto y alcabala a las donaciones destinadas a la redención; dar a la orden el importe de la manda si los testadores no incluyeran el nombre de los cautivos a sacar, en VÁzquez, Manual..., pp. 223-224 y 255; Adeline Rucquor, Valladolid en la Edad Media. El mundo abreviado (1367-1474), Junta de Castilla y León, Valladolid, 1997, pp. 257-258; Juan Iglesias Sanlés, "Paralelismo en la redención: las Partidas de Alfonso X y las Constituciones de Pedro Amer", Alcanate: Revista de estudios Alfonsíes, 2 (2000-2001), p. 202; Pedro A. Porras Arboledas, "Los privilegios reales de la Orden de la Merced en Castilla (1289-1500) y la Orden de Santiago", Cuadernos de Historia del Derecho, 22 (2015), Apéndice Documental, n 1, 2, 5, 8-10; César Olivera Serrano, "Las secuelas religiosas de un conflicto dinástico: portugueses en Castilla en el siglo XV", Poder, piedad y devoción. Castilla y su entorno. Siglos XII-XV, Isabel Beceiro Pita (dir.), Sílex, Madrid, 2014, pp. 172-173; Josemaría Revuelta Somalo, Los jerónimos, Institución Provincial de Cultura "Marqués de Santillana", Guadalajara, 1982, p. 88. 
(1430) e Isabel Arias (1472) y Sancha López (1396), a los de Segovia y Huete, respectivamente. Sin embargo, tal y como señala el contrato de patronato de la capilla mayor de Santa Catalina de Toledo adquirido por el comendador Lope Ortiz de Zúñiga, la orden no gozaba de sus mejores momentos en Castilla; el convento aceptó la cesión de la capilla porque

non sabian nin avian leydo que despues que por asaz años se avia enfriado el fervor de la devocion de su santa orden en las gentes seglares oviesen visto quien con tanta caridad y devoto corazon oviese querido tractar la dicha su orden partiendo con ella asy largamente de sus bienes y fazienda como el dicho Lope Ortiz?.

Desde los estadios iniciales, la Trinidad fue favorecida por los reyes peninsulares, expandiéndose rápidamente. Sus religiosos acompañaron a Fernando III en su campaña en el Valle del Guadalquivir, obteniendo tierras y casas en los repartimientos de los lugares conquistados, fundándose conventos en Úbeda (1234), Córdoba (1236), Jaén (1246) y Sevilla (1248). En este contexto llegaron a Murcia (1272), cuya fundación se atribuye a Alfonso X y los primeros frailes que llegaron a Valencia lo hicieron acompañando a Jaime I. En Mallorca se instalaron cuando les donó unas casas Constanza de Aragón, hermana de Jaime I y viuda de Guillermo Ramón de Montcada, fallecido durante la conquista. En Cuenca se constata su presencia en 1333. Fernando IV dio un privilegio similar al concedido a los mercedarios, influido por el provincial de Castilla y Portugal, su capellán (1304), al igual que Enrique II ante las quejas del provincial. Lo que se aprecia en ellos es la animadversión de los diferentes poderes e instituciones, al igual que en las intervenciones de Juan II, cuando suprimió sus privilegios y les prohibió demandar limosnas (1449), una de las mercedes más habituales que se concedieron a estas órdenes y a Guadalupe, monasterio que, como veremos, también estaba relacionado con las redenciones. No obstante, el rey defendió a los trinitarios de las autoridades locales, las cuales, cuando los religiosos iban a predicar, permitían otras demandas

\footnotetext{
María Fernández Pecha contribuyó con las obras de San Antolín de Guadalajara con una cantidad simbólica (1353), al igual que hicieron sus hermanas Beatriz (1358) y Mayor (1400), su madre Elvira Martínez (1374), Aldonza de Mendoza (1435) y su hermanastro, el I marqués de Santillana (1455). Teresa de Luna, tía de Álvaro de Luna, cuyo confesor era Juan de Huete, comendador de la Fuensanta de Cuenca, mandó sepultarse con el hábito mercedario y donó al monasterio cinco pedaços de panno de oro e otros predaços pequennos de panno de rexa raydos que yo dexo para reparo de un altar... siete tiras de lienço delgado que yo dexo que lo broslen mis doncellas que aqui seran nonbradas con el oro e plata e sirgo que yo dexo, e asi brosladas lo den al dicho monesterio (10/XI/1430), en AHN, Clero, Pergaminos, C. $576, \mathrm{~N}^{\circ} 1$ y 2; C. $577, \mathrm{~N}^{\circ} 4$; AHN, Clero, Libro 4.378, 12.541 y 16.033; AHNo, Frías, C. 522, D. 14; RAH, Salazar y Castro, M-123, ff. 21 a 32; Revuelta, Los jerónimos, pp. 88-93; VÁzquez, Manual..., p. 248; Francisco Layna Serrano, Historia de Guadalajara y sus Mendozas en los siglos XV y XVI, CSIC, Madrid, 1942, pp. 325-333; Jorge DíAz IBÁÑEz, El clero y la vida religiosa en Huete durante la Edad Media, Diputación de Cuenca, Cuenca, 1996, pp. 124-135 y La Iglesia de Cuenca en la Edad Media (siglos XII-XV). Estructura institucional y relaciones de poder, Tesis Doctoral, Madrid, 1996, pp. 457-458.
} 
destinadas a la redención (1453). El convento más favorecido por la familia real fue el de Valladolid, aunque también donaron a otros, como Pedro I al de Sevilla (1362)

Entre los linajes castellanos, los Estúñiga se vincularon a algunos conventos como los de Valladolid y Burgos, a los que varios de sus miembros hicieron donaciones, principalmente al primero, del que fueron patronos de la capilla mayor. En el caso de la Trinidad de Burgos, Enrique II colaboró con su traslado (c. 1371) y, tras ello, fueron miembros de la nobleza quienes lo protegieron, con predominio de los Manrique, además de los Mendoza y Rojas. Andrés Cabrera y Beatriz de Bobadilla favorecieron el monasterio de Graballa, cuando se integró en el marquesado de Moya. En cuanto al resto de estamentos, entre los miembros de la baja nobleza, Fernán Pérez de Acevedo y su esposa María de Aceves, fundaron la Trinidad de Toledo en época de Alfonso XI, el obispo de Salamanca, Diego de Anaya, trasladó a los trinitarios de la

8 Enrique II los tomó bajo su protección, mandó darles viandas y posada, no cobrar tributos por las cosas que llevasen, acompañarlos, ponerlos a salvo ante los peligros y consentirles pedir limosnas (1370). Juan II les prohibió demandar limosnas para concentrar esfuerzos económicos en la guerra contra el musulmán; el privilegio fue abolido para la Trinidad por petición de fray Juan Bonifaz y, años después, el rey hizo otra excepción permitiendo a los trinitarios pedir limosnas tras haberlo prohibido por el miedo de que un cautiverio prolongado los llevara a convertirse (1456). En Portugal ocurrió algo similar en la segunda mitad del siglo XV cuando el rey trató de apropiarse de su obra con una finalidad política. Ante las quejas de Alcalá, el rey aceptó que los legados de los vecinos fallecidos se gastasen en las labores de la villa y que no se diesen a las órdenes redentoras, como estaban haciendo cuando morían antes de ser liberados (25/VII/1386). Fernando IV tomó bajo su protección a la Trinidad de Valladolid (1311), la infanta Leonor, hija ilegítima de Enrique II, donó 3.000 maravedís (1412), al igual que hicieron varios miembros cercanos a la corte como la camarera de la reina Constanza, María Juan, y el canciller de María de Molina, Nuño Pérez de Monroy (1326). Pedro I donó 200 doblas a la Trinidad de Sevilla y la mitad a la Merced (1362), observándose la preferencia de los reyes castellanos por los trinitarios frente a los mercedarios. Los reyes aragoneses también protegieron la demanda de limosnas de los trinitarios: Pedro IV se dirigió a las autoridades del reino de Valencia a instancia de Pedro Berenguer, vicario del monasterio del Puig, ordenando que no se impidiese la colecta de limosnas en los días en que debía hacerse diebus dominicis et festivis et aliis consuetis diebus (21/I/1353). A Guadalupe, Pedro I autorizó su demanda a pesar de haber ordenado que sólo se permitiese recaudar la cruzada para poblar Algeciras y lugares fronterizos (1359); Enrique II ordenó que sus demandadores pudieran pedir limosnas por todo el reino, los eximió de tributación y mandó a sus oficiales que los defendiesen (1366); Juan II volvió a mandar a las autoridades que ayudasen a los colectores contra quienes impedían su labor (1445); Enrique IV lo autorizó a pedir limosnas para las obras aviendo consyderacion quel dicho monesterio es el mas notable de mys regnos e porque la obra del non cesase ni otrosy las dichas elimosnas e pias causas e obras meritorias que en el se han fecho e se fazen de cada dia (1456), en SErrano, El Cautiverio..., p. CDXXXIII-CDXXXV; AGS, PR, Leg. 31, No 41; Gervasio Velo y Nieto, "Don Nuño Pérez de Monroy abad de Santander", Hispania Sacra, 3 (1950), pp. 341-342; P. Giulio Cipollone, "La frontera entre los creyentes y el "pasaporte' por servicio humanitario de los 'trinitarios' redentores (1199)", Actas del Congreso de la Frontera Oriental Nazari como Sujeto Histórico (S. XIII-XVI), Pedro Segura Artero (coord.) Instituto de Estudios Almerienses, Almería, 1997, p. 133; Cassanyes, "La Iglesia...”, pp. 114-115; Díaz, La Iglesia ..., p. 474; Francisco de la Vega y Toraya, Chronica de la Provincia de Castilla, León y Navarra del orden de la Santíssima Trinidad, Segunda Parte, Joseph Rodríguez de Escobar, Madrid, 1723, pp. 48-50, 81, 121-122 y 173-179; Francisco J. Rojo Alique, "Testamento de doña Leonor, infanta de Castilla (1412)", Archivo Ibero-Americano, (271-273) 2012, pp. 197-199; Luis V. Díaz Martín, Colección documental de Pedro I de Castilla (1350-1369), Junta de Castilla y León, Valladolid, 1997, nº 1080; Revuelta, Los jerónimos, p. 177; AHN, Clero, Pergaminos, C. 406, No 5; C. 407, N 6; Iglesias, "Paralelismo...”, pp. 204-205. 
ciudad (1408) y su sucesor, Gonzalo de Vivero fundó Nuestra Señora de las Virtudes en Paradinas de San Juan (1460)9 .

Por tanto, la mayor parte de las fundaciones trinitarias y mercedarias, fueron patrocinadas por los reyes, quienes también concedieron una serie de privilegios a estas órdenes. Salvo escasos conventos erigidos por nobles cercanos a la corte, dicho estamento se limitó a hacer donaciones puntuales a algunos cenobios ubicados cerca de sus dominios o lugares de residencia. Sin embargo, como ya hemos apuntado, la Merced estuvo estrechamente relacionada con la Corona de Aragón, lo que llevó a los diferentes monarcas a emplear las órdenes redentoras como un elemento identitario de sus reinos, tomando las relaciones entre ambas partes, un cariz político.

\section{Las órdenes redentoras: una cuestión política y de identidad de las Coronas}

Los vínculos entre los reyes y las órdenes redentoras tuvieron connotaciones políticas e identitarias. En la fundación de la Orden de la Merced, el 10 de agosto de 1218, el obispo de Barcelona Berenguer de Palau y Raimundo de Peñafort dieron el hábito a Pedro Nolasco e incluyeron las barras del rey y de Aragón en el escudo de la orden. La importancia de este hecho fue tal que los procuradores de limosnas llevaban consigo bulas y privilegios para favorecer la colecta, sobre todo el de la concesión del escudo real. La primacía de la orden en dicha Corona también se manifiesta en el número de redimidos y en las mercedes obtenidas. Además, los reyes trataban de redimir cautivos de sus reinos: cuando Gregorio XI otorgó indulgencias a los que dieran limosnas para los cautivos (1377), Pedro IV temió que la Santa Sede centralizara los rescates y prohibió que el dinero saliera de sus reinos. Puede que el poco éxito de los trinitarios en

\footnotetext{
9 Al convento de Valladolid donó el justicia mayor, Diego López de Estúñiga (1357 y 1407) y al de Burgos, el mariscal Sancho de Estúñiga, su esposa Beatriz Manrique y la hija de ambos del mismo nombre. Es probable que el patronato de dicha capilla fuera adquirido a mediados del siglo XV por Rodrigo de Villandrando. Garci Fernández Manrique reconstruyó la Trinidad de Burgos (1375) recibió donaciones de Gómez Manrique (1410), su hija Sancha (1414) y los primeros condes de Castañeda, Garci Fernández Manrique (1436), su esposa Aldonza Téllez (1437-1445), Sancha Álvarez de Mendoza (1403), Juan Fernández de Rojas, Juan Rodríguez de Rojas y Juana de Toledo, esposa de Sancho Sánchez de Rojas (1387), en Manuel Villar y Macías, Historia de Salamanca. Libro IV. Desde el señorío de doña Constanza hasta el gobierno de don Alfonso Enríquez, Diputación Provincial de Salamanca, Salamanca, 1974, p. 63; VegA, Chronica..., pp. 89-104 y 182-188; Pedro LóPez de Altuna, Primera parte de la Crónica General del orden de la Santíssima Trinidad, Diego López Impresor, Madrid, 1723, p. 342; Díaz, La Iglesia..., p. 507; Ignacio Álvarez Borge, "Órdenes mendicantes y estructuras feudales de poder en Castilla la Vieja (siglos XIII y XIV)", Revista de Historia Económica, 3 (1999), p. 551; Lucía García Aragón, Documentación del monasterio de la Trinidad de Burgos (1198-1400), Fuentes medievales castellano-leonesas 28, Burgos, 1985, No 48, 88 y 103; AHNo, Osuna, C. 213, D. 65; RAH, Salazar y Castro, M-10, f. 352 v; M-59, ff. 96 a 108; M-123, ff. 1 a 8 y 21 a 32; O-1, ff. 239 a 245; Isabel Beceiro Pita, "La nobleza y las órdenes mendicantes en Castilla (1350-1530)", Poder, piedad y devoción. Castilla y su entorno. Siglos XII-XV, Isabel Beceiro Pita (dir.), Sílex, Madrid, 2014, pp. 325 y 335; AHN, Clero, Pergaminos, C. 204, No 3; C. 207, No 10; AHN, Clero, Legajo 1.053; AHN, Clero, Libro 16.797; Luis Salazar y CAstro, Pruebas de la historia de la Casa de Lara, Imprenta Real, Madrid, 1694, p. 56.
} 
Aragón tuviera que ver con su origen francés y el apoyo de Inocencio III a la orden, enemigo de los cátaros, a cuyo favor luchó Pedro II. A la rivalidad en el Languedoc entre Francia y Aragón, hay que añadir que varios generales trinitarios fueran consejeros y predicadores de los reyes franceses ${ }^{10}$.

El nombre de los generales mercedarios denota su carácter aragonés como Albert (13181330), Cantull, Bernardo de la Plaigen (1417-1419), Jaime de Aimerich (1419-1428) y Dullán (1429-1441). El primer general castellano fue Pedro de Huete (1441-1452) y la primera noticia de un provincial de dicho reino, Pedro Rodríguez Barrio, está constatada en el capítulo provincial de Sevilla (1361), donde también se verifican los primeros cuatro definidores con dicho origen. En el capítulo general de Játiva (1388) aparecen otros dos definidores castellanos, al igual que en el celebrado en dicho lugar el 28/IX/1419. En la elección de Bernardo de la Plaigen, hecha en Barcelona, no asistió ningún castellano, siendo elegido por aclamación. Otros como Ponce de Barellis (13481364) eran franceses, en este caso nombrado por Clemente VI, lo que fue reprochado por Pedro IV por no respetar a la orden ni a la Corona de Aragón. Ante la enfermedad de Nicolás Pérez en agosto de 1397, la orden temía que a su muerte el papa volviera a elegir general y pidió al rey aragonés que le escribiera para que les dejase elegirlo; no llegó a hacerlo, ya que el general se recuperó, falleciendo años después ${ }^{11}$.

En el procedimiento de redención de cautivos recogido en las Partidas, se vela por la seguridad del reino y, si se rescataban súbditos de otro reino con el que se estuviese en conflicto, se trataba de evitar el espionaje. Los mercedarios corrían el riesgo de ser confundidos con espías, como ocurrió en la campaña alfonsina de la conquista de Murcia. Según Tirso de Molina examinolos este amenazándolos de muerte si no le descubrían lo que les preguntase, instando a que dixessen si eran espias, los designios de le ynfante don Alfonso, el número de su exército y el sitio donde se hallaba ${ }^{12}$.

En otros aspectos del gobierno de los mercedarios se aprecia su aragonesismo, como el hecho de no existir dos provincias, sino que el general podía enviar vicarios o vi-

\footnotetext{
10 El arzobispo de Tarragona renunció a su privilegio de recibir limosnas para distribuirlas entre los cautivos en beneficio de la orden (1256), que logró hacerse con el monopolio de las demandas. Pedro IV derogó una autorización a los trinitarios que les permitía colocar bacines en iglesias y otros edificios públicos. Los vínculos con los mercedarios continuaron siglos después, como queda de manifiesto que, ante la creencia de que Nolasco participó en la conquista de Mallorca con el rey, fue canonizado en 1629 y se convirtió en su patrono diez años después. Varios generales trinitarios fueron consejeros y predicadores de los reyes franceses como Juan Boeleaud (1291), Tomás Loquet (c. 1330-1357) y Juan de Marchia (1378-1394), en Cassanyes, "La Iglesia...", pp. 116, 126-129; Zuriaga, La imagen..., pp. 48, 101 y 108; VÁzquez, Manual..., pp. 245-246; Iglesias, “Paralelismo...”, p. 204; López, Primera..., pp. 171-176 y 184. 11 Los cuatro definidores castellanos del capítulo de Sevilla fueron Gil de Huete, comendador del convento de Valladolid; Miguel de Guadalajara, de Toledo; Juan de Miranda, de Soria y Miguel, de Logroño. Los dos definidores castellanos en el capítulo de Játiva (1388) fueron Diego de Sevilla, comendador de Sevilla y Simón de Ágreda, de Guadalajara, por Castilla y Portugal. Los definidores castellanos elegidos para ir al capítulo de Játiva (1419) fueron Pedro de Valladolid, comendador de Salamanca y Juan de Toledo, de Guadalajara; el primero no asistió y en su lugar fue el comendador de Valladolid y provincial de Castilla, Juan de Granada, en VÁzquez, Manual..., pp. 206, 208, 224-228, 239-240, 263-265, 308-323 y 330-338.

12 Iglesias, "Paralelismo...", p. 205.
} 
sitadores y solo a partir de 1311 se reunían dos veces seguidas en Aragón y una en Castilla y, cada tres años, uno de estos capítulos sería general. En Castilla tuvieron roces frecuentes con los trinitarios, viéndose obligados a renunciar al derecho de pedir en las iglesias, encontrando mayor resistencia que en Aragón. En el capítulo general de Cuenca (1319) se redujo a siete el número de electores: el prior de Barcelona sería Vicario general en la vacante con el fraile más antiguo del convento y en las dos provincias habría cinco religiosos para elegir general: Cataluña, Aragón-Navarra, Valencia, Provenza-Mallorca y Castilla-Portugal. Tras la muerte del general Dulham (1441) se nombró a Nadal Gaver en abril, mientras que el obispo nombró a Pedro de Huete en mayo, separándose la provincia de Aragón que seguía a Gaver y, la de Castilla, a Huete. Tras varias vicisitudes, en 1452, tras la muerte de Huete, Gaver fue elegido general (1452-1474), produciéndose varios problemas que terminaron con una concordia que consagró la autonomía de la provincia de Castilla ${ }^{13}$.

Los vínculos que reflejaban una simple devoción llevaban detrás una cuestión política: la defensa de la identidad de la Corona. En el contexto de la guerra de los dos Pedros (1356-1369) y los conflictos entre ambas llevaron a las dos órdenes a presentar un proyecto de fusión al papa (1357) con la aprobación del general Barelli. Pedro IV pidió a este que no lo hiciera, manifestando su oposición a que se suprimiesen las barras de Aragón del escudo de la orden lo cual si se llevase a cabo redundaria indudablemente en deshonra nuestra y se quejó de que la orden acostumbraba a tener general aragonés (11/I/1358); de hecho, ya en las Constituciones de 1272 se prohibió la admisión de trinitarios y si algún mercedario pasaba a la Trinidad, se le prohibía su readmisión. La orden se vio privada de elegir general por la guerra entre Aragón y Castilla y, pese a estar convocados los electores, Urbano V nombró a Nicolás Pérez (5/I/1365), vicario perpetuo del Puig (1365-1401), para evitar los problemas de una vacante prolongada. En este contexto, el arcipreste de Hita, en su Libro del Buen Amor de mediados del siglo XIV, en el capítulo dedicado a la entrada de don Amor en Toledo, se refiere con estas palabras los de la trenidat con los frayres del Carmen, e los de Santolalla, porque no se desamen todos mandan que digan, que caten e que llamen 'Benedictus qui venit', responden todos 'Amen', haciendo referencia a las disputas entre ambas órdenes y pidiendo la concordia ${ }^{14}$.

Por tanto, pese a tener un cometido común, las órdenes de la Trinidad y la Merced tuvieron una historia diferente en virtud de sus relaciones con las dos Coronas peninsulares:

\footnotetext{
13 En la concordia de 1452 se redujeron las contribuciones de Castilla a las arcas de la orden, renunciando la provincia a los tres electores y en el capítulo de Almazán (1469) volvieron a nombrar uno por cada una; se devolvió a la Provincia de Castilla los conventos de Murcia y Lorca, agregados antes a Valencia, el de Burceña, filial de Pamplona, pasó a serlo de Logroño y se nombró una comisión para negociar y llegar a una concordia que mitigara la rivalidad entre las dos órdenes, en VÁzQuez, Manual..., pp. 15-16, 156-166, 171-183 y 349-369; ZuRIAGA, La imagen..., pp. 60-62 y 92-94.

14 Resulta curioso que El Corbacho (1438) se decante por los sermones mercedarios y no por los de los dominicos; esto puede deberse a que su autor, el arcipreste de Talavera, Alfonso Martínez, sustituyó como capellán de Juan II al predicador mercedario García de Meneses, en VÁzquez, Manual..., pp. 110-117, 232-235 y 245-246; Iglesias, "Paralelismo...", p. 204; Zuriaga, La imagen..., pp. 72-75.
} 
Castilla y Aragón. La cercanía de los mercedarios a la monarquía aragonesa llevó a los reyes a emplear a las órdenes redentoras como un elemento de identidad de sus reinos generándose conflictos entre ambas, en muchos casos, fruto de estas cuestiones políticas.

\section{La redención de cautivos: vías de recaudación, oposición del poder laico y di- námicas de los rescates}

En el siglo XIV el cautivo aún es visto como un trofeo y en la segunda mitad del XV comenzó a cambiar la mentalidad y fueron los ciudadanos quienes pidieron y contribuyeron económicamente con los rescates, provocando que la monarquía se involucrase y que la redención se convirtiese en una cuestión de "estado". Esto queda de manifiesto en otras intervenciones de los reyes. En primer lugar, intermediaron en los abusos de las órdenes redentoras hacia los testadores, como en las Cortes de Alcalá de 1348, donde una queja aludía a sus demandas, en el reino en general y en Toledo en particular, de las mandas en los testamentos a personas non çiertas; él rey respondió que porque esto es agora cosa nueva, quelo mandamos saber, et faremos sobre ello lo que fuere nuestro serviçio e pro de los de Toledo e de su regno. Se tomaron otras medidas para favorecer la redención: el concilio de Palencia ordenó confiscar los bienes a los clérigos concubinarios y destinar una tercera parte para la Trinidad y la Merced para que hicieran dicha labor (1388). Los vínculos entre estas órdenes y los reyes se vislumbran en otros hechos como el encuentro que tuvo lugar en Toledo entre Fernando IV y el provincial trinitario, Domingo Pardo, para llevarle cincuenta cautivos liberados en Fez y que el obispo mercedario de Lugo, Fernando Valdés (1403-1415), fuera predicador de Enrique III' ${ }^{15}$.

Los cronistas de ambas órdenes afirman que el siglo XIV fue poco favorable para la redención, al verse obligadas a pedir préstamos ante la pérdida de redentores y cautivos y tener que devolver con intereses lo prestado. El número estimado de cautivos nos es conocido gracias a una carta de Jaime II al papa donde el rey aragonés afirmaba que había unos 30.000 en Granada (1/XII/1311). No sabemos los rescates que realizaron los trinitarios en el siglo XIV, pero se calcula que durante las dos siguientes centurias liberaron a 7.445 en 24 redenciones y los mercedarios emprendieron 58 misiones en Granada redimiendo a más de 8.000 cautivos entre 1222 y 1482. Los precios a pagar dependían del estatus del cautivo, oscilando entre los 10 y 200 sueldos a comienzos del siglo XIII, aunque se han encontrado cantidades muy superiores, y en el siglo XV solía rondar los 15.000 maravedís; otras fuentes señalan que los valores oscilaban entre 7.000 y 10.000 maravedís en torno a $1470^{16}$.

\footnotetext{
15 Díaz, "Los Reyes...," p. 503; Cortes de los antiguos reinos de León y Castilla, Tomo I, Imprenta de M. Rivadeneyra, Madrid, 1861, pp. 605-606 y Tomo II, Imprenta de M. Rivadeneyra, Madrid, 1863, pp. 157-158; VÁzquez, Manual..., pp. 271-276; LóPez, Primera ..., pp. 170-172; Vega, Chronica ..., p. 80; Manuel Risco, España Sagrada. Tomo XLI. De la Santa Iglesia de Lugo: continuación de su historia desde el siglo XII hasta fines del XVIII, Viuda e hijos de Marín, Madrid, 1798, p. 131.

16 Las cantidades entregadas para redimir a un cautivo eran variadas, como los 11.000 maravedís pagados por Diego de Toledo, provincial trinitario en Castilla, para liberar a Antón Sánchez de Mures, vecino de
} 
Además, la tónica general del periodo bajomedieval fue la escasa simpatía mostrada por los poderosos hacia estas órdenes, en parte por ser mandas acostumbradas, lo que implicaba la obligatoriedad de los testadores de dejar una donación a las mismas, según disponía la legislación. Solían ser donaciones de pequeña entidad, lo que nos permite diferenciarlas de las ordinarias, reflejando su obligatoriedad y la poca voluntad de hacerla por parte del donante. Esto obedecía a los privilegios concedidos por Fernando IV a la Trinidad (1304) y la Merced (1311 y 1312) y confirmados por sus sucesores, en los que se establecían una serie de penas económicas para el testador, a favor de dichas órdenes, si omitía dejarles alguna manda. Sin embargo, como la redención era una de las principales obras de caridad, aparte de las mandas obligatorias, los testamentos contenían a veces otras destinadas a la redención de cautivos concretos ${ }^{17}$.

La nobleza, imitando a la Corona y manifestando su poder, incluyó cláusulas para la redención en sus testamentos. Los excautivos eran presentados ante los nobles o albaceas que patrocinaron su auxilio para que comprobasen que se había realizado, estando exentos de ello los redimidos por las órdenes religiosas. Algunos ordenaron vestirlos con ropas distintivas de su casa, como el I conde de Haro; los liberados por Fernando de Antequera en Sevilla, llevaban las mangas de los trajes encarnadas para realzar su condición de excautivos y Diego Arias Dávila mandó sacar doce cautivos, bien a través de un pago o cambiándolos por los moros e moras que tenía, ordenando que les diesen vestido, fuesen a sus tierras para que rogasen por él y su esposa y que pusiesen sus camisas enderredor de las paredes de mi capilla en la Merced de Segovia (1/I/1466) ${ }^{18}$. En un principio, en los testamentos se destinaba cierta cantidad para la redención genérica, sin indicar el beneficiario y, desde mediados del siglo XIII, iban dirigidas a las órdenes redentoras, la Cruzada y, en menor medida, para el rescate de un cautivo concreto. No obstante, hubo casos en que los albaceas continuaron haciéndolo de manera genérica, sin aludir a ninguna orden o persona. Esta actitud también tenía como fin evitar entregárselo a dichas órdenes, como ejemplifica la I condesa de Haro, quien mandó a ambas 200 maravedís e con esto los aparto e les pido que se ayan por contentos de qualquier otra manda que yo aqui faga sobre la redención, en clara alusión a los 300.000

Montilla y cautivo en Loja (c. 1470), en VÁzquez, Manual..., pp. 15-16, 110 y 128; Díaz, "Los Reyes”, p. 502; Iglesias, "Paralelismo...", p. 205; Ángel L. Molina Molina, "Episodios en las relaciones fronterizas entre los reinos de Murcia y Granada (siglos XIII-XV): los cautivos murcianos en tierra de moros y su liberación", Revista del CEHGR, 27 (2015), pp. 162-163; Emilio CABRERA, "Cautivos cristianos en el reino de Granada durante la segunda mitad del siglo XV", Relaciones exteriores del Reino de Granada: IV Coloquio de Historia Medieval Andaluza, Cristina Segura Graíno (coord.), Instituto de Estudios Almerienses, Almería, 1998, p. 231 y "De nuevo...”, p. 149.

17 En las Cortes de Alcalá (1348) hubo quejas ante los abusos de los procuradores de las dos órdenes por los privilegios que tenían de los reyes, gracias a los cuales tomaban las mandas hechas a lugares y personas desconocidas, la de mayor cuantía cuando se omitía dejarles una y los bienes de los que morían sin testar. Ante ello, Alfonso XI revocó los privilegios de ambas órdenes y eximió de la obligatoriedad de oír sus sermones, en VÁzquez, Manual..., pp. 211-213; CABrera, "De nuevo...", p. 152.

18 Elvira mandó 20.000 maravedís para rescatar tres cautivos (1463) y, al no haberse cumplido, su esposo los incluyó en los doce que ordenó redimir, en Serrano, El Cautiverio..., p. CCCLXXXVI-CCCLXXXVII; CONTRERAs, 2015: 468, 472 y 525-526. 
maravedís que donó a su hija, la abadesa de Santa Clara de Medina de Pomar, para que se los diese a la persona que fuera a sacarlos y otros 30.000 para las costas (1471). El comportamiento fue repetido por muchos poderosos, incluyendo entre las cláusulas que, si las órdenes se entrometían, pleiteaban o pedían más dinero, se cancelase la donación. Otros fueron más directos como el arzobispo de Sevilla, Alonso de Fonseca, quien mandó 70.000 maravedís para redimir cautivos a una persona fiel, ordenando que no sean entregados a la orden de la Trinidad ni de la Merced ni a sus frayles ni perlados ni a otras iglesias; dio permiso a estas órdenes para hacer la redención, siempre que fueran acompañados de dicha persona y esta llevase el dinero y a los liberados a Toro para presentarlos a su heredero, al que mandó que les diera vestidos (1460). Lo mismo dispuso Pedro Carrillo, quien ordenó llevar al liberado a su sepultura en Santo Domingo de Huete en tal manera que sea notorio que fue quito (1436) y Garci López de Trillo, quien añadió que los redimidos fuesen pobres y quedasen libres en sus tierras y no se llevasen a ningún lado, al contrario que los anteriores $(1437)^{19}$.

El dinero y la redención se podía entregar a un religioso determinado: el canónigo y vicario de Toledo, Pedro Fernández, lo confió en fray Toribio, comendador de Santa Leocadia (1358). También fue habitual encomendar dicha labor a un convento trinitario

\footnotetext{
19 A las órdenes redentoras y la Cruzada donaron: Alfonso Fernández de Córdoba, I señor de Cañete y adelantado de la frontera (1325); Leonor de Guzmán, señora del Puerto de Santa María (1341); Fernando Alfonso de Córdoba, II señor de Cañete y alguacil mayor de Córdoba (1343); Diego García de Toledo, señor de Mejorada y alcalde mayor de Toledo (1349); Juan Arias de la Reguera, señor de Espejo (1352); Diego López de Estúñiga, justicia mayor (1397 y 1407); Micer Alfonso Bocanegra, III señor de Palma (1384); Alonso Fernández de Vargas, señor de la Higuera de Vargas (1390); Sancha López (1396); Elvira de Bazán, señora de Toral (1408); Lope Gutiérrez de Córdoba, I señor de Guadalcazar y alcalde mayor de Córdoba (1409); Francisco Carrillo (1414); Teresa de la Vega, hija del almirante mayor, Diego Hurtado de Mendoza (1414); Inés de Loarte, mujer del regidor de Salamanca y comendador, Pedro Solís (1446); Pedro Carrillo de Huete (1446); Leonor de Arellano, señora de Aguilar (1447); Per Afán de Ribera II (1454); Hernando de Fonseca, señor de Coca y regidor de Toro (1463); Catalina Álvarez de Solís, señora de Romanillos (1469); Isabel Arias Dávila (1472). A la redención de manera genérica donaron: Mencía López, viuda del caballero Juan Alfonso (1401), Fernán Pérez de Ayala y María Sarmiento (1433 y 1436). Algunos poderosos dispusieron la cancelación de las mandas a las órdenes redentoras si se entrometían, pedían más dinero o ponían pleito como María Fernández Pecha, esposa del camarero Pedro González de Mendoza, quien donó 2.000 maravedís para sacar cautivos y otra cantidad ínfima y simbólica a las órdenes redentoras como manda acostumbrada (1353). Lo mismo hicieron Mencía García de Toledo, señora de Mejorada (1397); el adelantado Gómez Manrique (1410); Ruy González de Avellaneda (1436); Lope Vázquez de Acuña y su mujer, Teresa Carrillo (1446); Juana de Padilla mujer de Pedro Laso (1452); Catalina de Alcorcón, señora de Minaya (1462) y Alfonso Sánchez Dávila, oidor de la Audiencia (1470), en Rosa M. ${ }^{a}$ Montero Tejada, Nobleza y sociedad en Castilla. El linaje Manrique (siglos XIV-XVI), Caja Madrid, Madrid, 1996, pp. 381-382; Manuel Gónzalez García, Salamanca: la repoblación y la ciudad en la Baja Edad Media, Centro de Estudios Salmantinos, Salamanca, 1973, p. 95; Díaz, El clero..., p. 78; RAH, Salazar y Castro, F-8, ff. 80 a 84 v; M-10, ff. 95 a 96v. y 166 a 169 v; M-12, ff. 228 a 238 v; M-17, ff. 194 v. a 198; M-20, ff. 21 v. a 24 y 224v. a 227 v; M-23, ff. 294 v. a 295 v; M-36, ff. 173 v. a 176 v; M-37, ff. 85 v. a 86 v; M-43, ff. 177 a 182; M-45, ff. 38 a 39 v; M-47, ff. 243 a 256; M-48, ff. 4 v. a 7; M-51, ff. 211 a 223 v; M-60, ff. 275 v. a 278 v; M-72, ff. 362 a 367; M-114, ff. 61 a 68 ; M-124, ff. 166 a 168; M-131, ff. 94 a 111 v; O-1, ff. 239 a 245; ACSES, A/A, SAL. 13, No 1, ff. 21-29; AHN, Clero, Legajo 1.053 y 1.137; AHN, Clero, Pergaminos, C. $576, \mathrm{~N}^{\circ} 1$; C. $578, \mathrm{~N}^{\circ} 1$; C. 3.512, $\mathrm{N}^{\circ} 18$; AHN, Clero, Libro 4.378 y 12.541 ; AHNo, Frías, C. 598, D. 38-39.
} 
o mercedario en particular, como a los de Burgos, Valladolid, Badajoz, Sevilla, Córdoba, Segovia, Toledo, Guadalajara y Almazán. Otras veces se especificó a los cautivos que había que redimir, bien fueran estos conocidos o vasallos, incluso ordenando vender los cautivos propios para sacar a otros ${ }^{20}$.

20 A la Trinidad de Burgos donaron Sancho Fernández de Tovar, guarda mayor (1399); Sancha Álvarez de Mendoza (1403); Sancha, hija del adelantado Gómez Manrique (1414) y su esposa Sancha de Rojas (1437); Pedro Fernández de Velasco y su hijo Juan Fernández de Velasco (1414); Juan González de Pancorbo, escribano del rey (1453) y su viuda María López de Castro (1455). A la Trinidad y a la Merced de Valladolid, Juan Sánchez de Meneses, doce de Talavera (1402); Sancha Díez (1409); Juan Rodríguez, bachiller de Dueñas (1415); Sancho Martínez, arcediano de Campos (1418); Catalina Sánchez, viuda del mariscal Ruy Sánchez (1419); María González, viuda del bachiller Fernán González (1428); Pedro Álvarez Osorio, alférez mayor del pendón de la divisa y guarda mayor (1433); María Juan, camarera de la reina Constanza; María, hija del adelantado Gómez Manrique (1440); Diego López de Zúñiga, el Mozo, consejero del rey (1444); Beatriz, condesa de Buelna (1446); Alonso Niño, merino mayor de Valladolid (1466). A la Trinidad de Badajoz, Bernalt de Bearne, I conde de Medinaceli (1381). A Santa Catalina de Toledo, Tel Fernández, alcalde mayor de Toledo (1375); Martín Fernández de Guzmán, señor de Orgaz (1377); Urraca Rodríguez, brosladora de Catalina de Lancaster (1404); María de Guzmán, viuda del mariscal García González de Herrera (1413) y Hernán Álvarez de Toledo, I señor de Hijares (1438). A la Merced de Segovia, María García, esposa de Pedro González de Contreras (1379). A San Antolín de Guadalajara, Aldonza de Mendoza (1435), Men Rodríguez de Castro (1414), Teresa García (1447) y su marido, el bachiller Alfonso García de Peñalver (1468). A la Merced de Almazán, Leonor Núñez de Soto (1441). A la Trinidad y a la Merced de Sevilla, Pedro Ponce de León, IV señor de Marchena (1374); Per Afán de Ribera, adelantado mayor de la frontera (1421); Inés Gutiérrez de Haro, señora de Los Molares (1426); Diego Gómez de Ribera, adelantado mayor y notario mayor de Andalucía (1434); Juana Cabeza de Vaca, mujer de Lope Ortiz de Zúñiga (1441); Leonor de Guzmán, hija de Alvar Pérez de Guzmán, alguacil mayor de Sevilla (1441); Juan Ramírez de Guzmán, I señor de Teba (1463); Juan Ponce de León, II conde de Arcos (1469). A la Trinidad y a la Merced de Córdoba, Leonor López de Córdoba, hija del maestre de Calatrava (1428); Gonzalo Mesía Carrillo, VI señor de Santofimia (1467). Entre los que especificaron los cautivos a redimir, Diego Gómez de Ribera, adelantado mayor y notario mayor de Andalucía, mandó que sacasen en Málaga a Juan Carrillo Gallego, sobrino del prior de las Cuevas, Juan Fernández (1434); Pedro Ponce de León III, ordenó sacar los diez cautivos más pobres que pudiesen, preferiblemente sus vasallos (1448); el señor de La Albaida, Pedro González de Hoces, ordenó vender sus cautivos para sacar a Juan, Pedro, Fernando, Sancho, Antón y Esteban (1455), en RAH, Salazar y Castro, D-16, ff. 155-158; M-16, f. 26; M-17, ff. 210-214 v; M-22, ff. 244 v-257; M-24, ff. 1-4; M-25, ff. 176-180; M-36, ff. 292-311; M-43, ff. 160-166, 169v-174 y 195-199; M-51, ff. 11v-16; M-53, ff. 62-94v; 114v-119; M-128, ff. 327-329v; O-24, ff. 251v-255; José L. Barrios Sotos, Vida, Iglesia y Cultura en la Edad Media. Testamentos en torno al cabildo toledano del siglo XIV, Universidad de Alcalá, Alcalá de Henares, 2011, p. 198; Juan L. Carriazo Rubio, Los testamentos de la Casa de Arcos (1374-1530), Diputación de Sevilla, Sevilla, 2003, pp. 113, 135-140 y 151; Francisco de P. CAÑAs GÁlvez, "Urraca Téllez: Ascendencia social y proyección político-religiosa de una priora de Santo Domingo el Real de Toledo (ca. 1352-1431/32)", Mirabilia 17 (2013/2) Idealismo ou realidade da mulher na Idade Media, pp. 282-284; Luis SALAZAR y CAStro, Historia genealógica de la Casa de Haro (Señores de Llodio -Mendoza-, Orozco y Ayala, RAH, Madrid, 1959, pp. 347-353; Bonifacio Bartolomé Herrero, "Religiosidad y sociedad en la ciudad de Segovia durante la Edad Media", Poder, piedad y devoción. Castilla y su entorno. Siglos XII-XV, Isabel Beceiro Pita (dir.), Sílex, Madrid, 2014; VÁzquez, Manual..., pp. 193-195; CAntera, Los cartujos..., p. 201; AHN, Clero, Legajo, 1.015, 1.053 y 1.137; AHN, Clero, Pergaminos, C. 204, No 3; C. 3.447, No 13; C. 3.450, $\mathrm{N}^{\circ} 6$; C. 3.526, no 12; AHNo, Frías, C. 445, D. 10 y 41; C. 596, D. 12; AHN, Clero, Libro 4.378, 16.764 y 16.796; Esther GonzÁlez Crespo, Elevación de un linaje nobiliario castellano en la Baja Edad Media: los Velasco, Tesis Doctoral, Universidad Complutense de Madrid, Madrid, 1981, p. 237; AMSST, Pergaminos, Nº 4; LAYNA, Historia ..., pp. 310-314. 
Otros motivos de la desconfianza de los donantes pueden apreciarse en el compromiso de los mercedarios de devolver la manda en caso de que se perdiese, como ocurrió a comienzos del XV en el convento de Burgos y en el empleó el montante de la redención para otros fines. Esto último aconteció cuando Diego de Córdoba, guardián del convento de Ceuta, confesó haber recibido dinero para liberar a un cautivo, comprando con él un caballo (1477), ordenando venderlo para destinar su valor al rescate de su sobrino, cautivo en el "corral" de Granada para descargar su alma'

Al ser órdenes acostumbradas y existir la obligación de dejar una donación, los poderosos solían entregar cantidades ínfimas para evitar que estas órdenes se inmiscuyeran en las herencias de los finados como queda de manifiesto en numerosos testamentos. No obstante, linajes como los Velasco, Mendoza y Manrique dejaron grandes sumas y, en ocasiones, aunque escasas, se entregaron rentas perpetuas, como hizo el guarda mayor del rey, Sancho Fernández de Tovar, a la Trinidad de Burgos (1399). Lo anterior podía deberse a la cercanía de dichos personajes a la corte ya que, como indicamos previamente, la redención era una cuestión de la monarquía. En algunas donaciones destinadas a la redención, se vislumbra el cumplimiento de una penitencia por algún delito o abuso cometido. En esta línea, el caballero cacereño, Juan de Migolla, tras estar preso en Sevilla por haber intentado matar al maestre de Alcántara, Gutierre de Sotomayor, donó la mitad de sus bienes a la cartuja y la otra a los trinitarios de la ciudad (1444). El mismo proceder siguieron otros miembros de la nobleza y del patriciado urbano. Otro de los motivos de lo ínfimo de las mandas era el patrimonio de los nobles, que les permitía comprar la libertad ${ }^{22}$.

21 Iglesias, "Paralelismo...", pp. 205-207; CABrera, "De nuevo...”, p. 153.

22 Algunos entregaron pequeñas cuantías a la redención: Marina González mandó un maravedí a la Merced y Trinidad para que no se entremetan de las demandar los frayres de la Trinidat nin de la Merced deziendo que son mandas inciertas (1416); Juan de Robles, monje de San Benito de Valladolid, mandó 50 maravedís a ambas órdenes y con estos sean contentos y apartados deste mi testamento y de las mandas en el contenidas agora ciertos o enciertas (1432). Entre los que entregaron grandes sumas, la I condesa de Castañeda donó 15.000 maravedís e con esto los aparto de mis bienes (1441 y 1443); Juan de Velasco 2.000 florines de oro, el I conde de Haro 1.000 doblas de oro (1458) y 500.000 maravedís (1466). En la Trinidad confiaron María de Haro (1320); Beatriz, hija ilegítima de Enrique II (1409); Juan Hurtado de Mendoza, prestamero mayor de Vizcaya (1419); Teresa, hija del adelantado Gómez Manrique (1452). Otros destinaron dinero para la redención por alguna penitencia, como el bachiller Juan Rodríguez de Dueñas; Francisca Portocarrero, IV señora de Moguer y de Palma del Río (1436); Juan Mesía Carrillo, VII señor de La Guardia (1454) y el arzobispo de Sevilla, Alonso de Fonseca (1460), en Francisco J. Goicolea Julián, Haro: una villa riojana del linaje Velasco a fines del Medievo, Instituto de Estudios Riojanos, Logroño, 1999, p. 275; Antonio Moreno Ollero, Los dominios señoriales de la Casa de Velasco en la Baja Edad Media, Universidad de Valencia, Valencia, 2015, p. 362; Molina, "Episodios...", p. 165; Carlos Estepa Díez, "Dos testamentos femeninos en el siglo XIV: María de Haro y la reina María de Molina", Poder y sociedad en la Baja Edad Media. Estudios en homenaje al profesor Luis Vicente Díaz Martín. Tomo I, Carlos M. Reglero de la Fuente (coord.), Universidad de Valladolid, Valladolid, 2002, p. 381; AHN, Clero, Legajo 1.015 y 1.053; AMSST, Pergaminos, $\mathrm{N}^{\circ} 4$; AHN, Clero, Pergaminos, C. 3.449, $\mathrm{N}^{\circ} 15$; C. 3.453, $\mathrm{N}^{\circ}$ 14; AHNo, Osuna, C. 2023, D. 3; AHN, Clero, Libro 16.797; Santiago Cantera Montenegro, Los cartujos en la religiosidad y la sociedad españolas: 1390-1563, Tomo I, Universität Salzburg, Salzburg, 2000, p. 245; RAH, Salazar y Castro, M-12, ff. 228 a 238v; M-43, ff. 177 a 182; M-53, ff. 108 a 114; M-114, ff. 81 a 90; M-123, ff. 21 a 32. 
Además de lo anterior, las órdenes redentoras emplearon otras vías para la recaudación de fondos para la redención y para llevarla a cabo. La Trinidad incluyó en su Regla de 1198 la obligación de destinar una tercera parte de los ingresos de los conventos a la redención. La dificultad de su cumplimiento hizo que en siglo XIV el tercio fuera sustituido por una cantidad determinada en los capítulos provinciales, donde los conventos entregarían anualmente en función de su situación económica y en el Capítulo General que la Orden tuvo en la casa-madre de Cerfroid (1429), se convirtió en una cuota fija que cada convento tenía que pagar. Las constituciones mercedarias (1272), redactadas por el dominico Ramón de Peñafort, establecían que, si fuese preciso, los religiosos quedasen rehenes a cambio de la liberación de cautivos, regularizándose cuando llegó a considerarse un "cuarto voto" de los profesos, apareciendo por vez primera en $1565^{23}$. En ocasiones estas órdenes organizaban la predicación para recaudar fondos para la redención. Conocemos la que protagonizó fray Pedro de Moya entre mediados de febrero y finales de mayo de 1473 en La Serena, dependiente de la encomienda de la Merced de Córdoba. En esta ciudad, fue significativa la actividad de frailes procedentes de conventos lejanos, sobre todo, de la Trinidad de Arévalo y Burgos, ya que el dinero recaudado por los cenobios andaluces era gestionado por los de la Meseta. En 1478 se encontraban en la urbe Sancho de Laguna y Rodrigo Martín, trinitarios de Arévalo y Burgos respectivamente. En Córdoba, los laicos formaron cofradías o hermandades que se unían a la orden como donados y ayudaban con sus bienes a la redención, como ocurrió con la Hermandad de Jesucristo. Cada casa cubría una zona - contrata o bailía- donde los frailes recaudaban limosnas y, con el aumento del número de religiosos, se fueron convirtiendo en conventos. Los cuestores solían ser donados de la orden enviados por los frailes a una bailía para recolectar limosnas y se les requería honradez, llevar el hábito, jurar que no causarían daño a la orden y dar cuenta al comendador de lo recaudado ${ }^{24}$.

\footnotetext{
23 Cassanyes, "La Iglesia...", pp. 113-114; Serrano, El Cautiverio..., p. CDXXXIII-CDXXXV; Ruiz, "Redención...", p. 843; Iglesias, "Paralelismo...”, p. 207.

24 Antón Ruiz, vecino de Aguilar, reconoció haber recibido de Sancho de Laguna 12.000 maravedís para ayudar a redimir a su hijo Juan, preso en Loja desde hacía 17 meses, comprometiéndose a liberarlo en 20 días (25/I/1478); Juan Gómez, provincial de la Trinidad en Castilla, entregó en Sevilla 20 doblas castellanas para la liberación de Juanico que fue cautivo quando Los Molares, quien se comprometió a servir a la orden un año y un día; otras veces actuaron a distancia a través de procuradores: en 1472, Alfonso Pérez de Baena, hermano de la Santa Caridad, recibió de Bartolomé de Madrigal, vecino de Madrigal, 17.480 maravedís pagados en nombre de Sancho de la Cruz, ministro de la Trinidad, para rescatar dos cautivos; el de Arévalo confió en el de Burgos permitiéndole que, en su ausencia, actuase en su lugar tomando las cartas de obligación y recibiendo a los cautivos cuando llegasen (27/I/1478); en enero de 1478 Sancho de Laguna dio importantes cantidades para la redención, al igual que fray Rodrigo Martín. La primera noticia de la Hermandad de la Caridad data de la década de los setenta del siglo XV y puede que tuviera su sede en el monasterio de la Merced, al que ayudaron a rescatar cautivos; así lo ejemplifican el testamento de Lucía Fernández de Uceda, quien donó sus bienes a la Hermandad o a la Merced (1477) y Alfonso Pérez de Baena, miembro de la Hermandad, quien recibió de Alfonso de Fuenteovejuna, vicario del cenobio, en su nombre, 9.865 maravedís para sacar a Miguel de Escalona, cautivo en Montefrío (1476). Las hermanas de la Merced vivían en sus casas y colaboraron con los frailes cuidando a los redimidos, en CABRERA, “De nuevo...”, pp. 153-158 y “Cautivos...”, pp. 233-234; José E. LópeZ de Coca CASTAÑER, "La liberación
} 
En resumen, además de los privilegios regios destinados a garantizar la petición de limosnas por parte de las órdenes redentoras, los legados testamentarios y algunas disposiciones como la del concilio de Palencia, dichas órdenes emplearon otros medios para conseguir fondos y para redimir cautivos, ante la reticencia generalizada de los laicos de contribuir económicamente con las mismas.

\section{Monasterios de otras órdenes: redenciones, milagros y peregrinaciones}

Al margen de las órdenes redentoras, uno de los monasterios a los que se encargó la liberación de cautivos fue Guadalupe, a veces directamente, otras dejándole la decisión de encargar y entregar el dinero donado a una persona que fuese a redimirlos o compartiendo la labor con religiosos de otros conventos y órdenes como los cartujos. En el caso de Guadalupe, si bien no hay constancia de la obligación que suponía dejar una manda para las órdenes redentoras, se observan pequeñas donaciones por parte de los testadores. También se confió dicha labor a otros religiosos jerónimos, como hicieron Ruy González de Avellaneda y Juan Pacheco y, a dominicos, como el I conde de Haro. En Galicia, donde estas órdenes no poseían conventos, algunas cofradías recogían limosnas para la redención y se las entregaban a los mercedarios. En otros casos, se encargó a los cartujos la conversión de los cautivos que habían apostatado, como María de Aragón al prior de las Cuevas de Sevilla, Fernando de Torres, a otros religiosos de la orden como Rodrigo de Mella (1441-1442) y también se cometió la redención a laicos para evitar que fuesen los religiosos ${ }^{25}$.

de cautivos en la frontera de Granada (siglos XIII-XV), En la España Medieval, 36 (2013), pp. 102-104; Iglesias, "Paralelismo...", pp. 202-204.

25 A Guadalupe hicieron donaciones de pequeña entidad: Elvira Martínez (1374); Men Rodríguez de Castro (1414); Diego Hurtado de Mendoza (1400); Francisco Carrillo (1414), el señor de Totanés, Alfonso Carrillo, y la señora de Buenache, Teresa Carrillo (1472); el I señor de Hijares, Fernán Álvarez de Toledo (1438) y su hija María de Ayala, IV señora de Pinto (1471); Gonzalo López de Estúñiga, alcalde y justicia mayor de Molina (1378); Rodrigo Álvarez Osorio (1380); Juan Sánchez de Meneses, doce de Talavera (1402), Mencía de Fuensalida (1458); el oidor de la Audiencia, Alfonso Sánchez Dávila (1470) y Luis de la Cerda, señor de Villoria (1466). A Guadalupe encargaron la redención Egidio Bocanegra, V señor de Palma (1430); Teresa de Rojas, mujer del regidor de Talavera, Pedro Girón (1465); Lorenzo Suárez de Figueroa, I conde de Feria (1461); María de Aragón (c. 1445); Teresa Gil, esposa del I señor de Orellana (c. 1430); el III señor de Orellana (1471); Pedro Girón (1466); Ruy González de Avellaneda mandó sacar diecisiete cautivos a su mujer Isabel y su escudero Diego González de Avellaneda, o a un mercedario, trinitario o jerónimo en quien confiasen (1436) y Juan Pacheco mandó 800 ducados de renta a El Parral para que, cada diez años se entregase para redimir cautivos, ordenando que fuese un religioso del monasterio junto a un criado de su casa. El I conde de Haro renunció a las 1.000 doblas de oro que podía costar la sepultura, andas, cera y honras de su entierro en favor del prior de Cinco Altares de Rojas para que redimiera a todos los cautivos conocidos que pudiera, especialmente niños y mozas (1458). En las Cuevas confió Egidio Bocanegra, V señor de Palma (1430). Teresa Chacón, viuda de Juan de Cogollos, encargó la redención a laicos (1457), en RAH, Salazar y Castro, D-16, ff. 155 a 158; M-5, f. 30; M-9, ff. 361 a 364v; M-20, ff. 109 a 112; M-22, ff. 62 a 65, 237v. a 240 y 244v. a 257; M-42, ff. 200 a 201v; M-57, ff. 239v. a 241v; M-93, ff. 225-268v; M-96, ff. 84-96 y 159v-162; M-114, ff. 69-80; M-131, ff. 94 a 111v; AHN, Clero, Legajo 574 y 2.151; AHN, Clero, Pergaminos, C. 2.980 , No 13; C. 3.512, $\mathrm{N}^{\circ} 18$; C. 3.526, $\mathrm{N}^{\circ} 12$; AMG, 
En los siglos XIV y XV aparecieron milagros marianos vinculados a las redenciones en monasterios castellanos como Guadalupe y Santo Domingo de Silos y aragoneses, como Montserrat, importantes centros de peregrinación en los que se recopilaban, conservaban y difundían dichos milagros. Los tres primeros códices de Los Milagros de Guadalupe recogen 163 milagros de la Virgen redimiendo cautivos, desde principios del siglo XV a comienzos del XVI. Los peregrinos narraban los hechos milagrosos, un jerónimo lo redactaba, después era firmado por el peregrino y los testigos y, más tarde, otro fraile lo redactaba en extenso con sus nuevos aportes. Estos milagros eran un instrumento de propaganda para el monasterio y atraían peregrinos y donaciones. La devoción a la Virgen de Guadalupe se extendió por la Península, Francia, Inglaterra y Alemania, particularmente en las regiones fronterizas con los musulmanes, al estar vinculada con la redención. En estos casos no se pagaba el rescate sino que, a cambio de la liberación, los cautivos realizaban alguna promesa como ir en peregrinación al monasterio ofreciendo como exvotos las cadenas, otros símbolos de su cautiverio, limosnas y comprometiéndose a servirlo durante cierto tiempo ${ }^{26}$.

La redención interesaba a Guadalupe, ya que durante mucho tiempo los jerónimos trataron de redimir a cambio de dinero, lo que explica el aumento de cautivos que llegaban al monasterio para dar gracias a la Virgen y el gran número de milagros con esa temática. Sigüenza narra que el prior Gonzalo de Madrid (1447-1453), tras el saqueo y los cautivos tomados en Cieza por los musulmanes (1448), escribió a Juan II y a Álvaro de Luna culpándoles del mal abastecimiento de la frontera, los cautivos y los rescates. Al no hacer caso a la carta, el prior vendió las lámparas de plata que iluminaban a la Virgen, dejando solo una; hizo 100 marcos de plata de ellas y envió dos religiosos rescatáronse muchos cautivos y vinieron en procesión a Nuestra Señora de Guadalupe, celebrando su recibimiento aquel convento con lágrimas de ternura y devoción ${ }^{27}$.

Leg. 3, C. R-VI-4, doc. 15 y 15-a (bis); LóPez, “La liberación...”, pp. 88-90; SigüEnZA, Historia ..., p. 417; AHN, Clero, Libro 4.378; AHNo, Osuna, C. 225, D. 7; Frías, C. 1311, D. 5.

26 En la relación del viaje de Leon Rosmitahl (1465), escrita por Tetzel, se afirma que hacían falta más de 200 carretas para transportar el hierro depositado en Guadalupe. Jerónimo Münzer, que pasó por Guadalupe en 1494, destacó que los grilletes pesaban entre 25 y 40 libras. A mediados del siglo XVI aún había numerosos hierros y argollas colgados en las paredes según Pedro de Medina, en López, "La liberación...”, p. 87; Molina, "Episodios...”, pp. 155-156; Gerardo RodríGuez, "Los milagros en la religiosidad hispánica (siglos XIII al XIV)", Bulletin du centre d'études médiévales de Auxerre/BUCEMA, 2 (2009), http://journals.openedition.org/cem/9002 y "Elaboración de una devoción popular. Presencia bíblica en Los Milagros de Guadalupe (España, siglo XV)", Revista Mirabilia 3 (2003), pp. 196 y 201; M. ${ }^{\text {a Eugenia }}$ Díaz TENa, "Noticia sobre el estudio y edición de una colección de milagros marianos medievales: el C-1 de Los Milagros de Nuestra Señora de Guadalupe", La fractura historiográfica: las investigaciones de Edad Media y Renacimiento desde el Tercer Milenio, Javier San José Lara et alii (coords.), SEMYR, Salamanca, 2008, pp. 239-241 y 246-247; Juan Carlos Vizuete MendozA, "Los relatos de milagros, de la tradición oral al registro escrito en Montserrat, Guadalupe y la Peña de Francia”, El Patrimonio Inmaterial de la Cultura Cristiana, Francisco J. Campos y Fernández de Sevilla (coord.), Ediciones Escurialenses, San Lorenzo del Escorial, 2013, pp. 262, 268-270.

27 Alonso Pérez de Estarçena y el lisboeta Pedro, tras estar cautivos en Targua (Fez) doce y diez años, respectivamente, visitaron Guadalupe. Un trinitario viajó desde Málaga a Fez para liberar cautivos, gracias a las donaciones de caballeros andaluces -300.000 maravedís-y de Isabel I -gracias a un pecho que 
Algo similar ocurrió en el monasterio benedictino de Santo Domingo de Silos. Berceo tradujo y amplió una copia de los milagros (1225-1250) del abad Domingo (1041-1073), realizado por el monje Grimaldo a finales del siglo XI. En ella puso énfasis a los dedicados a la redención y los adaptó a un público mayor, principalmente a los peregrinos que iban a Santiago para que visitaran la tumba del santo. Al monje Pedro Marín se le atribuyen los Miraculos romançados de cómo saco santo Domingo los cautivos de la cautividad (1284-1285), con el fin de reactivar la fama del monasterio y atraer visitantes ante la competencia de otros situados en el Camino de Santiago como Nájera y Santo Domingo de la Calzada. Marín narra cómo la comunidad iba en procesión a la tumba del santo y los excautivos depositaban la prueba de su cautiverio, las cadenas, y hacían donaciones, principalmente para luminaria. Así hicieron catorce redimidos que llevaron el peso de sus cadenas en cera y, tras su regreso a sus respectivos lugares de origen, los liberados extendían la fama del monasterio. Los milagros del santo también quedan recogidos en otras fuentes como una bula de $1297^{28}$.

Juan Bautista Dameto refiere la intervención milagrosa en varias redenciones del que fuera abad de Oña, San Íñigo de Oña, siendo la prueba, de nuevo, "las muchas cadenas y grillos que estaban antes en la capilla deste santo”, que seguían allí en época comunera, cuando hicieron cuatro rejas grandes para defender el lugar y evitar que el hierro fuera robado para el conflicto. La redención de cautivos musulmanes en territorio cristiano también estuvo vinculada a monasterios, redimiéndose a varios de ellos a mediados del siglo XIII gracias al trabajo en las viñas y tierras del cenobio cisterciense femenino de San Clemente de Toledo durante cinco u ocho años ${ }^{29}$.

Como consecuencia de lo anterior, en la Baja Edad Media se popularizaron entre los poderosos las peregrinaciones a varios templos, destacando Guadalupe y, en menor medida, Santo Domingo de Silos y otros. Lo más frecuente fue el incumplimiento de algún voto realizado en vida de ir personalmente, por lo que incluyeron alguna manda en sus testamentos por la que enviaban algún peón que fuera por ellos para cumplir la

echó en la serranía de Ronda por el que obtuvo 700.000-; intentó liberar a Alonso y Pedro, pero los altos precios del rescate lo impidieron y los cautivos se encomendaron a la Virgen de Guadalupe aconsejados por el trinitario. Gracias a la intervención del prior se redimieron 50 cautivos, en Díaz, "Noticia...”, pp. 247-248; "Los Reyes...", pp. 499-501; RodRíguez, "Los milagros...".

28 De los milagros recogidos por Grimaldo hay siete de redenciones. La bula de 1297 ut ecclesia monasterium Sancti Domini de Silus, Burgensis diocesis, ubi divina potentia in honore ipsius beati Dominici maxima dignatur miracula operare, christianos captos et in Sarracenorum manibus redemptos de ipsorum manibus liberando facit eos supra mare, prout accepimus, siccis pedibus amulares, honoretur. En la iglesia se acumularon grilletes, colgados como exvotos, que los religiosos convirtieron en diversos objetos. La luminaria hacía perdurar la oración al encendida continuamente delante de la imagen. Fue tal la fama del santo que, acompañando en la conquista de Valencia a las tropas, al igual que en Mallorca, encontramos a Nolasco y a los mercedarios establecidos en el Puig de "Cebolla". Una mezquita convertida por los mercedarios en iglesia fue dedicada a Santo Domingo de Silos, en García, "Santo Domingo...", pp. 128-132 y 140; López, "La liberación...", pp. 86-87; Vizuete, "Los relatos...", p. 266; ZuriagA, La imagen..., p. 49.

29 José Manuel CALDERón OrTEga, "La liberación alternativa: reflexiones en torno a las fugas de cautivos y prisioneros durante la Edad Media hispánica”, Medievalismo, 18 (2009), pp. 29-30. 
promesa. En el códice de milagros, los hay relacionados con portugueses que peregrinaron a Guadalupe para agradecer la mediación de la Virgen y cumplir sus promesas, como cuando esta mandó a un león, símbolo de san Jerónimo, para guiar a los cautivos durante su liberación, al igual que hizo en la cautividad y enfermedad mortal de Juan Caldaira en Vélez de la Gomera (1496)

Alfonso XI visitó la ermita Guadalupe tras la victoria del Salado, ordenando reconstruirla y ampliarla para que tuviera cabida el gran número de peregrinos (25/XII/1340). Pedro I fomentó las peregrinaciones fundado un hospital que años después se denominó "Hospital del Obispo". Otros nobles, bien por su procedencia del sur peninsular, como Ruy Díaz de Berrio, señor de Carcabuey (14/VIII/1383) y Micer Alfonso Bocanegra, III señor de Palma (31/VIII/1384), o por haber sido cautivos, como el adelantado de Castilla, Gómez Manrique (21/IV/1410), enviaron peones al monasterio. Alfonso V de Portugal fue después de la campaña de Ceuta (1464). Esto nos induce a pensar que es posible que otras peregrinaciones como las de Juana Manuel, Enrique III (1402), Juan II y la familia real (1435), Blanca de Navarra (1440) y el condestable Miguel Lucas de Iranzo (1460 y 1461) tuvieran motivaciones similares. Junto a los peones podían mandar a alguno de sus vástagos como el señor de La Albaida, Diego de Hoces, a su hijo Jerónimo a velar una noche, ofrecer media arroba de cera que ardiese ante el altar, más el peso de su hijo en trigo y decir una misa con sus candelas (1464). Un siglo después, Cervantes peregrinó para agradecer a la Virgen su rescate manifestando que los peregrinos volvían los ojos a todas las partes del templo y les parecía ver venir por el aire volando los cautivos, envueltos en sus cadenas, a colgarlas de las santas murallas. Casi lo mismo, con otras palabras, decía un monje de Montserrat que predicaba a peregrinos del siglo XIV

vienen descalzos y de rodillas, con sus ofrendas al cuello, cuales con cirios y blandones y vestes y mortajas. Aquí veréis venir alguno con el dogal al cuello... Como así mismo muchas veces llegan otros de muy lejanas tierras, y son los que habiendo caído cautivos en poder de los sarracenos, invocaron devotamente a esta Santísima Virgen de Montserrat, por ella han sido milagrosamente librados de dicha esclavitud, y vienen aquí con sus grillones de hierro, manoplas y cadenas para ofrecerlas a la celestial Señora... muchas argollas y cadenas, grilletes y manillas y demás instrumentos de horror de diversas personas milagrosamente libertadas de la cautividad y la cárcel $^{31}$.

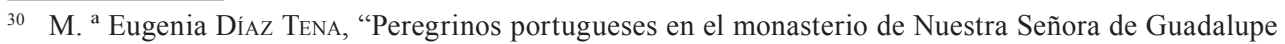
(siglo XV)", Península, Revista de Estudios Ibéricos, 4 (2007), pp. 71-72.

31 Sancha, hija del adelantado Gómez Manrique, envió peones al monasterio (1414), en M. Filomena CERRo Herranz, Documentación del monasterio de Guadalupe. Siglo XIV, Diputación Provincial de Badajoz, Badajoz, 1987, n 7; Francisco de P. CAÑAS GÁlvez, "Devoción mariana y poder regio: las visitas reales al monasterio de Guadalupe durante los siglos XIV y XV (ca. 1330-1472)”, Hispania Sacra, LXIV-130 (2012), pp. 433-443; AHN, Clero, Legajo 1.053; RAH, Salazar y Castro, M-48, ff. 61v. a 64; M-114, ff. 61 a 68; Miguel Herguedas Vela, Patronazgo real en los monasterios jerónimos de la Corona de Castilla:
} 
En menor grado que Guadalupe, los poderosos enviaron peones a otros monasterios como Santo Domingo de Silos, como hizo Sancha Martínez de Deza (1400). María López Pacheco, viuda de Tristán Silva lo encargó a la Trinidad y a Guadalupe, para cumplir una promesa que hicieron cuando estuvieron presos, sustituyendo el destino por el más cercano de la Peña de Francia (1459). Alvar Pérez Osorio, alférez del pendón mayor de la divisa, no es extraño que acudiera a las campañas andaluzas, mandando a tres caballeros con dos escuderos de su séquito, además de a Guadalupe, al crucifijo de San Agustín de Burgos y a la Peña de Francia (1469). Así se entiende también que el cronista fray Manuel da Esperança relacionase la entrega de Santa María de las Virtudes por el infante Eduardo de Portugal a los franciscanos observantes (1428) con una supuesta promesa que Juan I (1385-1433) y su hijo hicieron durante la conquista de Ceuta; una vez más, queda de manifiesto los vínculos entre la conquista de territorios musulmanes y la redención con los monasterios ${ }^{32}$.

En conclusión, de forma paralela a las redenciones llevadas a cabo por las órdenes redentoras, aparecieron otros templos que trataron de competir con las mismas en dicha labor. Entre ellos, Guadalupe y Santo Domingo de Silos jugaron un papel de primer orden, si bien, no tanto a través de la redención material de los cautivos, sino mediante la creación de relatos míticos en los que la Virgen o el santo titular del cenobio, eran protagonistas de la liberación. Esto llevó a la extensión de la costumbre de las peregrinaciones a dichos santuarios, reportando, además de fama, importantes ingresos a estos cenobios.

\section{Conclusiones}

Además de una cuestión religiosa y económica, los vínculos entre los reyes y las órdenes redentoras tuvieron connotaciones políticas que, en términos generales se resumen en los estrechos vínculos entre la monarquía aragonesa y la Orden de la Merced y un mayor alejamiento de los trinitarios. Esto queda de manifiesto en la presencia de las barras de Aragón en el escudo de la orden, leyendas que implicaban al fundador de la orden en hechos trascendentales de la política aragonesa, el origen aragonés de sus generales, el origen francés de los trinitarios o los conflictos entre ambas órdenes en Castilla.

Ambas órdenes gozaron de la benefactoría y protección de los reyes, por ser la redención una cuestión de "estado" que atañía a la monarquía. Sin embargo, no tuvieron buena recepción entre los testadores por ser mandas acostumbradas y la consiguiente penalización económica si omitían dejar una donación en sus últimas voluntades. Esto se aprecia en que la mayoría de las mandas a estas órdenes son ínfimas y simbólicas,

Arte y Arquitectura, Tesis Doctoral, Universidad de Valladolid, Valladolid, 2017, p. 173; Vizuete, "Los relatos...", pp. 266-267.

32 AHN, Clero, Pergaminos, C. 203, No 14; C. 1.876, No 4; AHNo, Astorga, C. 1, D. 1; Diana Lucía Gómez-CHACón, "Apariciones marianas y renovación monástica en la Castilla bajomedieval: Guadalupe y Santa María la Real de Nieva", Los monasterios medievales en sus emplazamientos: lugares de memoria en lo sagrado, Fundación Santa María la Real, Aguilar de Campoo, 2016, pp. 237-238. 
para evitar las correspondientes sanciones económicas y en los frecuentes encargos de redenciones a laicos para evitar que las llevaran a cabo estas órdenes. Sin embargo, la liberación de cautivos daba prestigio a los nobles y sus linajes, ordenando en muchos casos llevar a los redimidos a la capilla familiar en algún monasterio, donde se colgaban sus vestimentas y cadenas en recuerdo de la misericordia del noble o portar las vestimentas de su linaje como acto propagandístico. No obstante, algunas donaciones destinadas a redimir cautivos se hicieron como penitencia por abusos previos.

Las escasas simpatías del poder laico hacia las órdenes redentoras llevaron a estas a buscar otras fuentes de financiación para los rescates. Dichas fuentes podían provenir de disposiciones de concilios como el de Palencia, de los privilegios reales y de las medidas internas de las órdenes. Al margen de la Trinidad y la Merced y, aprovechando la animadversión del poder laico hacia ellas, otros monasterios y órdenes se encargaron de la redención, como los cartujos, benedictinos y dominicos. En Castilla Guadalupe, Santo Domingo de Silos u Oña y en Aragón, Montserrat, se encargaron de compilar y difundir varios milagros relacionados con la labor intercesora y milagrosa de sus Vírgenes o santos titulares en la redención de cautivos. En el caso de San Clemente de Toledo, aconteció lo contrario: varios cautivos musulmanes fueron redimidos por su trabajo durante varios años en las tierras y viñas del monasterio.

Gracias a lo anterior, estos monasterios consiguieron, no solo aumentar el número de peregrinaciones, exvotos, donaciones y contribución a las obras u otro tipo de servicios por parte de los redimidos, sino también, de varios miembros de la nobleza, contribuyendo a la extensión de su fama. Nos queda la duda de si, varias peregrinaciones de miembros de la familia real castellana y portuguesa y la de varios nobles, de los que se desconocen las causas, pudieran tener que ver con la redención o a la conquista de alguna plaza musulmana, como se atestigua en otros casos. Aunque muchas veces no se indique el motivo, el hecho de que muchos de los nobles que prometieron peregrinar o enviar peones a estos monasterios procedían del sur, algunos habían sido cautivos y otros fueron después de alguna campaña contra el musulmán, también es un indicio de que lo hicieran movidos por dichas causas.

Por tanto, las relaciones entre el poder laico con las órdenes redentoras de cautivos durante la Baja Edad Media, se pueden resumir en una protección por parte de la monarquía y un alejamiento de los nobles hacia ellas, convirtiéndose en una cuestión de índole política, religiosa, social y económica.

\section{Bibliografía citada}

\subsection{Fuentes inéditas}

ACSES, A/A, SAL. 13, No 1.

AGS, PR, Legajo 31, doc. 41. 
AHN, Clero, Legajos 574, 1.015, $1.053,1.137$ y 2.151.

AHN, Clero, Libro 4.378, 12.541, 16.033, 16.764, 16.796 y 16.797.

AHN, Clero, Pergaminos, C. 203, No 14; C. 204, No 3; C. 207, No 10; C. 406, No 5; C. $407, \mathrm{~N}^{\mathrm{o}} 6$; C. $576, \mathrm{~N}^{\mathrm{o}} 1$ y 2 ; C. $577, \mathrm{~N}^{\mathrm{o}} 4$; C. $578, \mathrm{~N}^{\mathrm{o}} 1$; C. $1.876, \mathrm{~N}^{\mathrm{o}} 4$; C. 2.980 , $\mathrm{N}^{\mathrm{o}} 13$; C. $3.447, \mathrm{~N}^{\mathrm{o}} 13$; C. $3.449, \mathrm{~N}^{\mathrm{o}} 15$; C. $3.450, \mathrm{~N}^{\mathrm{o}} 6$; C. $3.453, \mathrm{~N}^{\mathrm{o}} 14 ;$ C. $3.512, \mathrm{~N}^{\mathrm{o}}$ 18 ; C. 3.526, $\mathrm{N}^{\mathrm{o}} 12$.

AHNo, Astorga, C. 1, D. 1.

AHNo, Frías, C. 445, D. 10 y 41; C. 522, D. 14; C. 596, D. 12; C. 598, D. 38-39; C. 1311, D. 5.

AHNo, Osuna, C. 213, D. 65; C. 225, D. 7; C. 2023, D. 3.

AMSST, Pergaminos, $\mathrm{N}^{\circ} 4$.

AMGuadalupe, LEG. 3, carp. R-VI-4, doc. 15 y 15-a (bis);

RAH, Salazar y Castro, D-16, F-8, M-5, 9, 10, 12, 16, 17, 20, 22, 23, 24, 25, 36, 37, $42,43,45,47,48,51,53,57,59,60,72,93,96,114,123,124,128,131$, O-1, O-24.

\subsection{Fuentes impresas}

Cerro Herranz, M. ${ }^{a}$ Filomena, Documentación del monasterio de Guadalupe. Siglo XIV, Diputación Provincial de Badajoz, Badajoz, 1987.

Cortes de los antiguos reinos de León y Castilla, Tomo I, Imprenta de M. Rivadeneyra, Madrid, 1861.

Cortes de los antiguos reinos de León y Castilla, Tomo II, Imprenta de M. Rivadeneyra, Madrid, 1863.

Díaz Martín, Luis V., Colección documental de Pedro I de Castilla (1350-1369), Junta de Castilla y León, Valladolid, 1997.

García Aragón, Lucía. Documentación del monasterio de la Trinidad de Burgos (11981400), Fuentes medievales castellano-leonesas 28, Burgos, 1985.

López de Altuna, Pedro, Primera parte de la Crónica General del orden de la Santíssima Trinidad, Diego López Impresor, Madrid, 1723.

Risco, Manuel España Sagrada. Tomo XLI. De la Santa Iglesia de Lugo: continuación de su historia desde el siglo XII hasta fines del XVIII, Viuda e hijos de Marín, Madrid, 1798.

Salazar y Castro, Luis, Historia genealógica de la Casa de Haro (Señores de Llodio -Mendoza-, Orozco y Ayala, RAH, Madrid, 1959.

Salazar y CAstro, Luis, Pruebas de la historia de la Casa de Lara, Imprenta Real, Madrid, 1694.

Sigüenza, José de, Historia de la Orden de San Jerónimo, Tomo I, Junta de Castilla y León, Valladolid, 2000. 
VÁzQuez NúÑEz, Guillermo, Manual de la Historia de la Orden de Nuestra Señora de la Merced, Editorial Católica Toledana, Toledo, 1931.

Vega y Toraya, Francisco de la, Chronica de la Provincia de Castilla, León y Navarra del orden de la Santíssima Trinidad, Segunda Parte, Joseph Rodríguez de Escobar, Madrid, 1723.

\section{Bibliografía}

Álvarez Borge, Ignacio, “Órdenes mendicantes y estructuras feudales de poder en Castilla la Vieja (siglos XIII y XIV)”, Revista de Historia Económica, 3 (1999), pp. 543-578. Barrios Sotos, José L., Vida, Iglesia y Cultura en la Edad Media. Testamentos en torno al cabildo toledano del siglo XIV, Universidad de Alcalá, Alcalá de Henares, 2011.

Bartolomé Herrero, Bonifacio, "Religiosidad y sociedad en la ciudad de Segovia durante la Edad Media", Poder, piedad y devoción. Castilla y su entorno. Siglos XII-XV, Isabel Beceiro Pita (dir.), Sílex, Madrid, 2014, pp. 125-160.

Beceiro PitA, Isabel, "La nobleza y las órdenes mendicantes en Castilla (1350-1530)", Poder, piedad y devoción. Castilla y su entorno. Siglos XII-XV, Isabel Beceiro Pita (dir.), Sílex, Madrid, 2014, pp. 319-358.

CABrera, Emilio, "Cautivos cristianos en el reino de Granada durante la segunda mitad del siglo XV", Relaciones exteriores del Reino de Granada: IV Coloquio de Historia Medieval Andaluza, Cristina Segura Graíño (coord.), Instituto de Estudios Almerienses, Almería, 1998, pp. 227-235.

Cabrera, Emilio, "De nuevo sobre los cautivos cristianos en el reino de Granada", MERDIES, III (1996), pp. 137-160.

Calderón Ortega, José M., "La liberación alternativa: reflexiones en torno a las fugas de cautivos y prisioneros durante la Edad Media hispánica”, Medievalismo, 18 (2009), pp. 11-44.

Calderón Ortega, José Manuel y Díaz GonzÁlez, Francisco Javier, "El rescate de prisioneros y cautivos durante la Edad Media hispánica. Aproximación a su estudio", HID, 38 (2011), pp. 9-66.

Cantera Montenegro, Santiago, Los cartujos en la religiosidad y la sociedad españolas: 1390-1563, Tomo I, Universität Salzburg, Salzburg, 2000.

Cañas Gálvez, Francisco de P., "Devoción mariana y poder regio: las visitas reales al monasterio de Guadalupe durante los siglos XIV y XV (ca. 1330-1472)", Hispania Sacra, LXIV-130 (2012), pp. 427-447.

Cañas Gálvez, Francisco de P., "Urraca Téllez: Ascendencia social y proyección político-religiosa de una priora de Santo Domingo el Real de Toledo (ca. 1352-1431/32)", Mirabilia 17 (2013/2) Idealismo ou realidade da mulher na Idade Media, pp. 273-304. 
Carriazo Rubio, Juan L., Los testamentos de la Casa de Arcos (1374-1530), Diputación de Sevilla, Sevilla, 2003.

Cassanyes Roig, Albert, "La Iglesia de Mallorca y la redención de cautivos en la Baja Edad Media", en Espacio, Tiempo y Forma. Serie III. Historia Medieval, 32 (2019), pp. 105-132.

Cipollone, P. Giulio, “La frontera entre los creyentes y el 'pasaporte' por servicio humanitario de los 'trinitarios' redentores (1199)", Actas del Congreso de la Frontera Oriental Nazarí como Sujeto Histórico (S. XIII-XVI), Pedro Segura Artero (coord.) Instituto de Estudios Almerienses, Almería, 1997, pp. 117-136.

Contreras Jiménez, M. ${ }^{a}$ Eugenia, Linaje y transición histórica: los Arias Dávila entre el medievo y la modernidad, Tesis Doctoral, Universidad Complutense de Madrid, Madrid, 2015.

DíAz IBÁÑEz, Jorge, El clero y la vida religiosa en Huete durante la Edad Media, Diputación de Cuenca, Cuenca, 1996.

DíAz IbÁÑEZ, Jorge, La Iglesia de Cuenca en la Edad Media (siglos XII-XV). Estructura institucional y relaciones de poder, Tesis Doctoral, Madrid, 1996.

Díaz Tena, M. ${ }^{\text {a }}$ Eugenia, "Peregrinos portugueses en el monasterio de Nuestra Señora de Guadalupe (siglo XV)”, Península, Revista de Estudios Ibéricos, 4 (2007), pp. 65-77.

Díaz Tena, M. a Eugenia, "Los Reyes Católicos y la redención de cautivos en un milagro mariano de finales del siglo XV (I)", Literatura medieval y renacentista en España: líneas y pautas, Natalia Fernández Rodríguez y María Fernández Ferreiro (coords.), SEMYR, Salamanca, 2012, pp. 499-506.

DíAz TenA, M. a Eugenia, "Noticia sobre el estudio y edición de una colección de milagros marianos medievales: el C-1 de Los Milagros de Nuestra Señora de Guadalupe", La fractura historiográfica: las investigaciones de Edad Media y Renacimiento desde el Tercer Milenio, Javier San José Lara et alii (coords.), SEMYR, Salamanca, 2008, pp. 239-249.

Estepa Díez, Carlos, "Dos testamentos femeninos en el siglo XIV: María de Haro y la reina María de Molina", Poder y sociedad en la Baja Edad Media. Estudios en homenaje al profesor Luis Vicente Díaz Martín, Tomo I, Carlos M. Reglero de la Fuente (coord.), Universidad de Valladolid, Valladolid, 2002, pp. 375-392.

García de la Borbolla, Ángeles, "Santo Domingo de Silos, el santo de la frontera: la imagen de la santidad a partir de las fuentes hagiográficas castellano-leonesas del siglo XIII", Anuario de Estudios Medievales, 31/1 (2001), pp. 127-145.

Goicolea Julián, Francisco J., Haro: una villa riojana del linaje Velasco a fines del Medievo, Instituto de Estudios Riojanos, Logroño, 1999.

GonzÁlez CRespo, Esther, Elevación de un linaje nobiliario castellano en la Baja Edad Media: los Velasco, Tesis Doctoral, Universidad Complutense de Madrid, Madrid, 1981. 
GonzÁlez García, Manuel, Salamanca: la repoblación y la ciudad en la Baja Edad Media, Centro de Estudios Salmantinos, Salamanca, 1973.

Herguedas Vela, Miguel, Patronazgo real en los monasterios jerónimos de la Corona de Castilla: Arte y Arquitectura, Tesis Doctoral, Universidad de Valladolid, Valladolid, 2017.

Iglesias SAnlÉs, Juan "Paralelismo en la redención: las Partidas de Alfonso X y las Constituciones de Pedro Amer", Alcanate: Revista de estudios Alfonsíes, 2 (2000-2001), pp. 201-208.

Layna Serrano, Francisco, Historia de Guadalajara y sus Mendozas en los siglos XV y XVI, CSIC, Madrid, 1942.

López de Coca Castañer, José E., "La liberación de cautivos en la frontera de Granada (siglos XIII-XV)", En la España Medieval, 36 (2013), pp. 79-114.

Lucía Gómez-Chacón, Diana, "Apariciones marianas y renovación monástica en la Castilla bajomedieval: Guadalupe y Santa María la Real de Nieva", Los monasterios medievales en sus emplazamientos: lugares de memoria en lo sagrado, Fundación Santa María la Real, Aguilar de Campoo, 2016, pp. 211-244.

Molina Molina, Ángel L. "Episodios en las relaciones fronterizas entre los reinos de Murcia y Granada (siglos XIII-XV): los cautivos murcianos en tierra de moros y su liberación", Revista del CEHGR, 27 (2015), pp. 145-165.

Montero Tejada, Rosa M. ${ }^{\text {a }, ~ N o b l e z a ~ y ~ s o c i e d a d ~ e n ~ C a s t i l l a . ~ E l ~ l i n a j e ~ M a n r i q u e ~(s i g l o s ~}$ XIV-XVI), Caja Madrid, Madrid, 1996.

Moreno Ollero, Antonio, Los dominios señoriales de la Casa de Velasco en la Baja Edad Media, Universidad de Valencia, Valencia, 2015.

Olivera Serrano, César, "Las secuelas religiosas de un conflicto dinástico: portugueses en Castilla en el siglo XV", Poder, piedad y devoción. Castilla y su entorno. Siglos $X I I-X V$, Isabel Beceiro Pita (dir.), Sílex, Madrid, 2014, pp. 161-188.

Porras Arboledas, Pedro A., "Los privilegios reales de la Orden de la Merced en Castilla (1289-1500) y la Orden de Santiago", Cuadernos de Historia del Derecho, 22 (2015), pp. 319-358.

Revuelta Somalo, Josemaria, Los jerónimos, Institución Provincial de Cultura "Marqués de Santillana”, Guadalajara, 1982.

Rodríguez, Gerardo, "Elaboración de una devoción popular. Presencia bíblica en Los Milagros de Guadalupe (España, siglo XV)", Revista Mirabilia 3 (2003), pp. 192-211. Rodríguez, Gerardo, "Los milagros en la religiosidad hispánica (siglos XIII al XIV)", Bulletin du centre d'études médiévales de Auxerre/BUCEMA, 2 (2009), http://journals. openedition.org/cem/9002.

Rojo Alique, Francisco J., "Testamento de doña Leonor, infanta de Castilla (1412)", Archivo Ibero-Americano, (271-273) 2012, pp. 191-214. 
RucQuoI, Adeline, Valladolid en la Edad Media. El mundo abreviado (1367-1474), Junta de Castilla y León, Valladolid, 1997.

Ruiz BarRera, M. a Teresa, "Redención de cautivos. Una especial obra de misericordia de la Orden de la Merced", La Iglesia española y las instituciones de caridad, Francisco Javier Campos y Fernández de Sevilla (coord.), Instituto Escurialense de Investigaciones Históricas y Artísticas, El Escorial, 2006, pp. 841-862.

Sancho Gómez, Celia, "Violencia y cautiverio al sur del reino de Valencia a principios del siglo XV: Elche como un observatorio de una villa de frontera", Norba. Revista de Historia, 25-26 (2012-2013), pp. 311-338.

Serrano del Toro, Andrés, El Cautiverio en la Frontera Murciano-Granadina en el siglo XIV: un Fenómeno Socio-Económico, Tesis Doctoral, Universidad de Murcia, 2015. Velo y Nieto, Gervasio "Don Nuño Pérez de Monroy abad de Santander", Hispania Sacra, 3 (1950), pp. 319-360.

Villar y Macías, Manuel, Historia de Salamanca. Libro IV. Desde el señorio de doña Constanza hasta el gobierno de don Alfonso Enríquez, Diputación Provincial de Salamanca, Salamanca, 1974.

Vizuete MendozA, Juan Carlos, "Los relatos de milagros, de la tradición oral al registro escrito en Montserrat, Guadalupe y la Peña de Francia", El Patrimonio Inmaterial de la Cultura Cristiana, Francisco Javier Campos y Fernández de Sevilla (coord.), Ediciones Escurialenses, San Lorenzo del Escorial, 2013, pp. 261-280.

Zuriaga Senent, Vicent F., La imagen devocional en la orden de Nuestra Señora de la Merced. Tradición, Formación, Continuidad y Variantes, Tesis Doctoral, Universitat de Valencia, 2005. 